\title{
A Selective Review of the Risk Factors for Antisocial Behavior across the Transition to Adulthood
}

\author{
Joanne Savage ${ }^{1}$, Stephanie K. Ellis ${ }^{2}$, Kathryn Kozey ${ }^{1}$ \\ ${ }^{1}$ Department of Justice, Law and Society, American University, Washington DC, USA \\ ${ }^{2}$ Department of Sociology and Criminal Justice, Marymount University, Arlington, USA \\ Email: jsavage@american.edu
}

Received April $9^{\text {th }}$, 2013; revised May $11^{\text {th }}$, 2013; accepted June $10^{\text {th }}, 2013$

Copyright (C) 2013 Joanne Savage et al. This is an open access article distributed under the Creative Commons Attribution License, which permits unrestricted use, distribution, and reproduction in any medium, provided the original work is properly cited.

\begin{abstract}
In this paper, we discuss the theory and research on a select set of risk factors for continuity in antisocial behavior across the transition to adulthood. Several risk factors (e.g., early onset, intelligence, marriage, employment) are based on Moffitt's dual taxonomy and the age-graded theory of social control. In addition, we also review studies of impulsivity, school enrollment, educational attainment, academic achievement, abuse victimization, social support, poverty, deviant peers, drug and alcohol abuse, and criminal justice intervention.
\end{abstract}

Keywords: Transition to Adulthood; Risk Factors; Antisocial Behavior; Crime; Marriage

\section{Introduction}

The transition to adulthood has been receiving increasing attention as an important stage in development in recent years. One essential focus of the literature is the persistence of antisocial behavior into young adulthood. One reason this particular outcome is important because, in some ways, it signifies a failure in certain developmental sequences. Another reason for its importance is a practical one. Offending in adulthood is viewed much differently in the criminal justice system than is juvenile delinquency. In contrast with the juveile justice system, where efforts are generally made to shepherd wayward youths back to the fold, the adult criminal justice system, referred to anachronistically as a "corrections" system, emphasizes accountability and often includes an intentionally harsh punitive component, reflecting a shift in societal expectations for adult behavior and responsibility. Thus, understanding what causes some juvenile delinquents to perpetrate criminal behavior after the age of 18 has significant practical implications, and is likely to be useful for creating interventions and prevention programs that may have the enhanced dividend of keeping some individuals from ever going to adult prison.

In this paper we will review what is currently known about a selection of risk factors for persistence in antisocial behavior from adolescence into young adulthood. We say "persistence" because few offenders initiate offending in adulthood, but rather continue offending from adolescence. Thus, predictors of "persistence" are likely to be nearly identical to predictors of young adult offending.

\section{Moffitt's Taxonomy}

The most well-known theory about the development of persistent antisocial behavior is Moffitt's dual taxonomy. Moffitt (1993) predicted that life-course-persistent offending is likely to result from a combination of neuropsychological risks and environmental risks. Her own review of the first ten years of research suggests that support for this hypothesis has been quite strong (Moffitt, 2006a). Her theory makes several predictions related to stability of offending, early onset, and intellectual function; these are among the risk factors discussed below.

\section{Crime and the Life Course}

The life-course perspective in criminology emphasizes the importance of both continuity and change in offending over time. The most prominent contemporary theorists in this area, Sampson and Laub (e.g., 1993), introduced the age-graded theory of informal social control, emphasizing the role of social bonds in the inhibition of antisocial behavior (expanding earlier work by Hirschi, 1969). Robins (1966) had earlier observed that while most antisocial adults were antisocial children, not all antisocial children become antisocial adults, and Sampson and Laub have used this fact to bolster their position that social bonds change over time and important transitions in these bonds can lead to dramatic changes in offending. In particular, Sampson and Laub highlight the importance of transitions into adulthood such as marriage, employment, or military service. If the quality of the bonds established in these transitions is high, they argue that these "turning points" are likely to lead to desistance in antisocial conduct (Sampson \& Laub, 1993). We will review studies about the impact of work and marriage on young adult offending below.

\section{Other Risk Factors for Persistent Antisocial Behavior from Adolescence to Adulthood}

There are six other risk factors which we will discuss here that do not emanate directly from the basic propositions emphasized in theoretical work by Moffitt or by Sampson and 
Laub: impulsivity; school enrollment, attainment and achievement; abuse victimization; social support; poverty; deviant peers; alcohol and drug use; and criminal justice intervention. Measures of behavioral regulation have been used in many studies to predict aggressive behavior and conduct problems, including persistent conduct problems in childhood. It was Gottfredson and Hirschi's (1990) seminal book, propounding the general theory of crime, which brought low self-control to the attention of criminologists as a potential cause of long-term antisocial behavior. As a result, "self-control" is probably the most studied "personal factor" in the etiology of criminal behavior and the research on low self-control and persistent offending will be discussed here. School is central to the life of children and adolescents and may also yield an enormous impact on young adult behavior. Abuse victimization in childhood and adolescence is thought to have long-term consequences through its traumatic effects and influence on social learning. Social support in young adulthood might be expected to buffer the adverse effects of stressors that cause offending, so it is also included here. Situational factors, such as poverty, friendship with deviant peers, and the abuse of alcohol or drugs are also believed by many to play an important role in offending in the emerging adult years.

\section{Person Factors}

\section{Stability of Offending}

The best predictor of current antisocial behavior is usually some measure of previous aggressive or antisocial behavior. Authors of virtually all the major, recent, longitudinal studies of childhood aggression and later delinquency report evidence for continuity over time.

Although stability has been seen by many as a "person" factor, due to a criminal "trait," the reasons for stability are much more complex. Some stability in antisociality is probably due to genetic and biological factors that directly impinge on behavior such as risk-taking. In addition, however, ongoing exposure to an environment which elicits antisocial behavior can also cause stable behavior (e.g., Patterson, Reid, \& Dishion, 1992; Sampson \& Laub, 1993). The exposure to environmental effects such as weak social bonds, poor parenting, delinquent peers, and high-crime communities is likely to be an ongoing problem which influences criminal activity over time, regardless of individual propensity. Moffitt (1993) suggested that persistent criminality would arise from a combination of neuropsychological deficits and a disadvantaged environment. Vila (1994) argues that antisocial behavior is influenced by biological and developmental risk factors, but criminal propensity is analogous to criminal "strategic styles" which take shape due to the differential reinforcement of force, fraud, or stealthful behavior. Finally, some authors intromit the reciprocal influence of behavior, reminding us that past behavior has an effect on current contextual factors that might influence antisocial behavior today (e.g., Laub \& Sampson, 2003). For example juvenile delinquency can cause parents to reject their children. Expulsion from school can cause later unemployment. Violent behavior can result in punishment through the criminal justice system-which can attenuate prosocial bonds and foster friendships with other delinquents. These contextual factors in turn adversely influence later behavior. Wright, Caspi, Moffitt and Silva (2001) add an interaction based on their "life-course interdependence" view, arguing that prosocial ties, like educa- tion, and antisocial ties, like association with deviant peers, are likely to have a greater influence on those high in criminality. The role of factors that cause a person to be more vulnerable to risk is likely to be significant in predicting continuing antisocial behavior.

\section{Early Onset of Antisocial Behavior and Continuity across the Transition to Adulthood}

"Early onset" is the only risk factor for persistent offending about which we conclude that a consensus has been reached. Recognition that early onset is a strong and consistent predictor of chronic offending has been present for a long time. That conclusion has not changed in recent research. Fergusson, Horwood, and Nagin (2000) concluded that early onset conduct problems and early onset attention problems were associated with chronic offending. Early acting out behavior, conduct disorder, age at first conviction and related problem behavior have all been associated with later chronic offending in numerous datasets (e.g., Blokland, 2005; Cottle, Lee, \& Heilbrun, 2001). More research is needed to assess the generalizability of the effect across demographic groups.

\section{Intelligence}

Moffitt's theory features "neuropsychological” factors and she has operationalized these as cognitive tests including early undercontrolled temperament, neurological abnormalities, delayed motor development, low intellectual ability, reading difficulties, poor memory, hyperactivity, and slow heart rate (Moffitt \& Le Blanc, 2003). Moffitt (2006b) cites a variety of neurodevelopmental and neurocognitive factors that are differentially associated with later membership in life-coursepersistent offending groups such as low intellectual ability, reading difficulties, and poor scores on neuropsychological tests of memory. She reports that persistent serious offenders in her study showed the greatest deficits on standard neuropsychological tests.

Many studies have reported a negative association between intellectual function and chronic offending (e.g., Cottle et al., 2001; Farrington, 2000; Raine, Loeber, Stouthamer-Loeber, Moffitt, Caspi, \& Lynam, 2005; Sampson \& Laub, 2003). If we limit ourselves to studies predicting offending in early adulthood from earlier indicators of intellectual function, there are many whose findings are consistent with the theory that lower intelligence predicts young adult offending (e.g., Farrington, 2000; Fergusson et al., 2000; Sampson \& Laub, 1993; Werner \& Smith, 1992).

\section{Impulsivity}

A meta-analysis by Pratt and Cullen (2000) suggests that the association between indicators of self-control and offending is frequently statistically significant, but weak in longitudinal studies. We conclude that findings from studies focusing on young adult offending are consistently supportive (e.g., DeLisi \& Vaughn, 2008; Piquero, Farrington, \& Blumstein, 2007). DeLisi and Vaughn (2008) examined data from a sample of juvenile offenders and found that those identified as "career offenders" (divided at the 90th percentile on the Career Criminality Index) had lower self-control than other offenders. In their study, "...low self-control was overwhelmingly the strongest predictor of career criminality" and "far exceeded" the impact of other factors including gender, race, and traumatic experience (p. 520).

Lahey and Loeber (1997) point out that while several pro- 
spective longitudinal studies report that children with ADHD exhibit antisocial behavior later in life, the analyses do not control for other conduct disorders. Because attention problems and hyperactivity are frequently comorbid with childhood conduct problems, and these are fairly "stable" over time, the authors concluded that studies of the independent effect of ADHD had "failed to provide an unambiguous answer to this question" (p. 56). In research on young adult criminality, at least two studies have tested the predictive association of hyperactivity on young adult criminal outcomes and found no empirical connection when they controlled for conduct problems. These latter findings suggest that the predictive value of impulsivity may be low since the effects may be confounded with conduct problems already evident before young adultood.

\section{Education and School}

Many studies suggest that school factors are associated with delinquency and it is common that offenders have very significant school problems. School factors are potentially quite useful because children in most industrialized countries are required to attend school, and it provides opportunities to identify high risk individuals.

\section{School Enrollment, Drop-Out and Educational Attainment}

We might anticipate that school enrollment and attainment would be associated with young adult offending for two principal reasons. First, being in school (post-secondary school in this case) is likely to keep the individual occupied in a non-criminogenic environment, reduce routine activities associated with criminal places, and foster associations with non-criminal friends. Second, greater school attainment is associated with many goods related to socioeconomic status and employment opportunity, and is likely to lead to association with non-deviant friends and residence in a low-crime community. Being in school has been associated with lower offending among young adults in the Pittsburgh Youth Study (Stouthamer-Loeber, Wei, Loeber, \& Masten, 2004), and in a sample of convicted offenders (Horney, Osgood, \& Marshall, 1995). More studies would be needed to draw a firm conclusion.

Dropout is of serious concern, but the findings have been ambiguous. We found only a few studies of its impact on offending in young adulthood and two of them support the idea that academic attainment is significantly, negatively associated with criminal behavior in young adulthood. At least three major studies, however, have found contradictory evidence. For example, in the Cambridge data, "junior school" attainment did not distinguish high-rate chronic offenders (Piquero et al., 2007). More research is clearly needed to elucidate the associations between dropout/attainment and persistence in offending.

\section{Academic Achievement}

Academic achievement has been negatively associated with many criminal outcomes in a great many studies, including those of chronic offending. Authors have reported significant associations between placement in special education programs and chronic offending (e.g., Cottle et al., 2001). Doing poorly in school has been associated with classification into a high-rate offending trajectory group by the end of high school in several studies. Associations between grade point average, usually in high school, and young adult offending have been negative and significant in other studies as well (e.g., Arum \& Beattie, 1999).

In data presented by Johnson, McGue, and Iacono (2009), changes in antisocial behavior from age 17 to 24 were significantly associated with age $17 \mathrm{GPA}$, in a conservative model which also included parental SES, IQ, reading score, and age 24 educational attainment. Subsequent genetically-informed analysis of the data suggests that age 17 GPA is largely due to genetic factors and some non-shared environmental factors, leading the authors to conclude that the association between school performance and later antisocial behavior is due to individual characteristics that exist by age 17. Because GPA is an easy measure to acquire, its utility as a predictor is promising, even if it may really be a proxy for genetic factors.

\section{Abuse Victimization}

Severe abuse also features prominently in literature about serious antisocial behavior. There is a general consensus that maltreatment predicts delinquency and Pagani (2009) includes corporal punishment and violence in families in her review of family factors in the etiology of persistent criminality.

Findings on the association between abuse victimization and young adult offending are consistent. A meta-analysis conducted by Cottle et al. (2001) indicated that a history of physical or sexual abuse is associated with juvenile recidivism and Widom (1989) found associations between early abuse and both violent and nonviolent criminal behavior. Studies have shown that childhood neglect and physical abuse are associated with young adult offending, early onset and persistent delinquency (e.g., Thornberry, Henry, Ireland, \& Smith, 2010; Werner \& Smith, 1992) and that severe punishment is associated with early onset offending. Adult violent offending has also been associated with the extent of physical punishment in childhood (e.g., Cohen, Kasen, Smailes, \& Fagan, 2002).

\section{Social Support}

Parents, families and conventional sources of support (partners, friends, clergy, etc.) can wield an impact on antisocial behavior as the adolescent becomes an adult. Social support has many recognized benefits that may impact chronic offending. For example, when provided on a consistent basis and in a prosocial context, social support has the potential to strengthen social bonds, improve psychological well being, provide access to information and other resources, and perhaps most importantly, buffer the impact of stress and other negative life events (e.g., Cullen \& Wright, 1997; Ellis \& Savage, 2009).

There are relatively few empirical studies on the impact of social support on persistent offending, but the findings so far suggest a promising direction for research. Bui and Morash (2010) found that successful adult female parolees made changes in their social networks after incarceration, dissolving relationships that promoted criminal activities (including drug use), and establishing new relationships or reestablishing ties with supportive family members. Several other studies have reported negative and significant associations between social support and offending in young adulthood (e.g., Ellis \& Savage, 2009; Wiesner \& Windle, 2004). We expect that social support might be especially important for women and for vulnerable populations such as re-entering offenders and young adults leaving foster care.

\section{Situational Factors}

\section{Poverty}

Poverty blocks access to the fundamental requirements of life 
(food, decent shelter, etc.) and creates severe stress. It is likely to have an influence on offending in young adulthood, especially if the young adult does not have financial support from family. Some authors have made the case that childhood poverty can have a lasting impact on the developing child due to financial stress in the family (reducing the amount or quality of supervision of children and potentially lowering academic attainment or achievement). Families in poverty are also often plagued by other problems associated with delinquency such as low parental education and residence in disadvantaged neighborhoods.

There are numerous studies that suggest that recidivistic, chronic offending is most common among the poor and in poor communities (e.g., Cottle et al., 2001; Fergusson et al., 2000; Moffitt, 2003). In the Cambridge study, high-rate chronic offenders were more likely to come from low income families than high adolescence-peaked offenders and other offenders (Piquero et al., 2007). Hoeve et al. (2007), however, did not find an association between family SES and delinquency in the long term. Poverty is one of the few factors that we might expect to predict adult-onset offending, for example in cases where the young person is suddenly expected to be financially independent and does not have adequate resources. This is most likely to happen among children with weak ties to family or foster children.

\section{Deviant Peers}

We might expect that interaction with deviant peers would be a very important influence on offending in the transition to adulthood (e.g., Bui \& Morash, 2010). A meta-analysis suggests that delinquency of peers is associated with juvenile recidivism (Cottle et al., 2001). Several studies of delinquency trajectories suggest that antisocial peers are most common among those on the highest or escalating trajectories in adolescence (e.g., Ayers, Williams, Hawkins, Peterson, Catalano, \& Abbott, 1999).

Some scholars have proposed that peer influence is less important among chronic offenders than other types of offenders (e.g., McGloin \& Stickle, 2011; Moffitt, 1993). For example, Moffitt proposes that life-course-persistent offenders begin offending prior to the time that peers become highly influential. However, peers may play an important role for persistent offenders through co-offending, or group offending. McGloin and Stickle (2011) observe that offending with others is often one of the consistent markers of career criminals. Association with deviant peers may also reinforce antisocial tendencies and may lead to spontaneous offending, especially in the presence of suitable targets (McGloin \& Stickle, 2011). McGloin and Stickle (2011) hypothesized that chronic offenders would be "less likely to offend because of delinquent peers, but just as likely to offend with them” (p. 425). They found that chronic offenders in their sample were less likely than nonchronic offenders to report peer influence as the reason for their deviant behavior, ranking it last. Yet chronic offenders were just as likely as nonchronic offenders to engage in co-offending.

\section{Employment}

Life-course theorists have emphasized that employment represents an important turning point in the transition to adulthood (Sampson \& Laub, 1993). The empirical evidence on work and young adult offending has been mixed. Most authors anticipate a beneficial effect of employment, due to the likelihood of reduced economic stress, prosocial bonds, and fewer idle hours in the company of delinquent friends. However others have argued that the unemployed are less likely to go out and encounter criminal opportunities that spur spontaneous criminal behavior. In some samples, high-rate offenders are less likely to have a job than other subjects and job stability has been negatively associated with recidivism, but Horney et al. (1995) report that their subjects committed more property crime while they were employed and one other study reports no significant association between employment and desistance. In light of these mixed findings, further research is clearly needed. Important questions regarding the differential effects of employment on youth versus adults, and the potential confounding influences of income level, criminal opportunities with coworkers, and changes in routine activities associated with work remain to be probed further.

\section{Marriage}

In Sampson and Laub's work, marriage is a key turning point likely to influence desistance in young adulthood. Many authors have reported a negative association between marriage and measures of offending. Qualitative data collected by Laub and Sampson (2003) suggest that many desisters credit marriage as a major turning point in their offending careers (though these interviews were carried out well beyond "emerging adulthood"). Divorce and separation were "conspicuously absent” in their desister group. Whether this was due to an abiding bond, as the authors have argued, or to greater supervision, is uncertain (said one subject: “She won't put up with any baloney”).

Though the preponderance of findings is supportive of Sampson and Laub's hypothesis about marriage, the robustness of the relationship has been called into question. For example, Warr (1998) controlled for delinquent friends, and found that the relationship between marriage and desistance was no longer significant, bringing to light the importance of careful statistical modeling for future research.

It is also likely that certain qualities of the marital bond affect young adult offending in different ways. For example, some authors have distinguished between early, hasty marriages, and later marriages. The findings thus far are inconclusive on that point. Werner and Smith (1992) found that a second marriage "not infrequently" had a restraining effect, while a marriage in response to a "hasty teen pregnancy" did not (p. 117). In the Cambridge study, a recent analysis, using propensity scores to control selection bias, found that a reduction in offending occurred only among those who married in young adulthood, ages 18 - 24, and not those who married later (Theobald \& Farrington, 2009). Sampson and Laub have come to emphasize enduring marriage in their work, and there is an emerging consensus that enduring marriage has a beneficial effect on offending (e.g., Laub, Nagin, \& Sampson, 1998); significant associations have been found in several data sets.

Because marriage and "enduring marriage" are not randomly distributed in the population, it is likely that any effects they might exert are partly due to sample bias. Those who get married and stay married may be more likely to desist from crime due to a host of underlying characteristics or circumstances that predict good outcomes and differ from their unmarried counterparts. Thus, recent research on marriage and offending has employed two approaches to address this problem. One way to 
reduce sample selection biases is to control for "propensity" to marry (and stay married). Farrington and West (1995) used a case control design on a small sample of men who got married in the Cambridge Study who could be matched very closely on number of prior convictions with other subjects who remained unmarried for at least five years. Although the married and unmarried men had incurred the same number of convictions before marriage, those who married had significantly lower convictions in the following five years than those who did not get married. In fact, the conviction rate for the unmarried men was close to two times that for the married individuals when they extended the follow-up to age 32 (or until the married individuals were separated from their spouses). The design is clever, but does not eliminate the possibility that the married and unmarried subjects differed in other important ways. In another study, propensity score matching was used to disentangle effects of selection bias with the same result (King, Massoglia, \& MacMillan, 2007).

Another way to address the sample selection problem is to use a within-subjects design and examine the effects of being married or unmarried on individual offending over time. Studies using these designs have, on the whole, found that being married is associated with lower offending in young adulthood. The weakness of these designs is that they must eliminate rival hypotheses linking "being married" in a given year and offending. While it is easy to control for factors such as income or age, such studies have not adequately controlled for factors such as "maturity" which might cause both successful marriage and desistance from antisocial behavior. In a very complex analysis of the Glueck and Glueck follow-up sample, employing "inverse probability of treatment weighting” (IPTW) to control for confounds related to selection bias in married subjects as well as within-subjects sources of bias, Sampson, Laub and Wimer (2006) estimated an average reduction of approximately 35\% in the odds of committing a crime when a given subject was married compared to not married. More research employing propensity score matching and within-subjects designs is needed to test the tightly confined research question (is it really being married that changes the behavior?). Nonetheless, marriage as observed in the population, encompassing all the reasons a person gets married and stays married, appears to be associated with lower rates of offending.

\section{Drug and Alcohol Abuse}

Many authors have expected that drug and alcohol abuse in the transition to adulthood would increase offending. Although early reviews reported that the evidence on associations between drug use and criminality were not conclusive, emergent research is leaning in the direction of an association between alcohol and drug abuse and persistent offending (e.g., Benda et al., 2001; Stouthamer-Loeber et al., 2004). The effect in this particular life period may be especially potent since drug use disorders peak during this time, drug use does not decline as precipitously as other types of criminality, and, in the US and many other cultures, emerging adults are awarded the legal right to drink alcohol as freely as they wish.

\footnotetext{
Alcohol

In Laub and Sampson's (2003) qualitative data, alcohol abuse was common in the life histories of persistent offenders. Quantitative studies have reported statistically significant associa-
}

tions between heavy episodic drinking and fighting, alcohol use and chronic offending, and adolescent drunkenness and young adult offending.

Findings by Horney et al. (1995) indicate that the association may be confounded. They used a retrospective month-by-month survey to examine the association between certain life circumstances and offending in a sample of Nebraska serious offenders. Controlling for other factors such as whether or not the offender was on probation, in school, employed, and living with a wife, "heavy drinking" was not significantly associated with criminal behavior. Authors of at least one other recent study have reported similar findings. Hussong, Curran, Moffitt, Caspi, and Carrig (2004), who entitle their paper, "Substance abuse hinders desistance...” used a time-varying covariate model to predict the future trajectory of criminal non-drug-related antisocial behavior, and estimate whether or not alcohol was associated with an upward departure from that trajectory. They found that men with more symptoms of alcohol abuse reported significantly higher antisocial behavior than expected at ages 18 and 21; the effect was marginally significant at age 26 as well. Thus, alcohol abuse is a risk marker for young adult offending, but more research is needed to understand the amount of alcohol associated with the effect and whether the association is fully mediated by other factors.

\section{Illicit Drug Use}

On the balance, the preponderance of studies have shown fairly convincing support for a drug use-persistence association (e.g., Horney et al., 1995; Morizot \& Le Blanc, 2007; Schroeder, Giordano, \& Cernkovich, 2007; Wiesner \& Windle, 2004), but some contradictory findings leave some questions unanswered. First, it is not yet clear whether drug use predicts ongoing serious crime, or is limited mainly to drug crime and drug-related crime. It is also likely that different drugs and different levels of drug use affect offending in young adulthood in different ways, but such a small number of studies examine specific drug types, or distinguish between heavy and casual use, that no conclusions can be drawn at this time.

\section{Behavior and Its Consequences}

\section{Criminal Justice Intervention for Prior Delinquency}

Unfortunately, while just about every response to juvenile offending is intended to reduce the likelihood of future offending, evidence suggests that criminal justice responses often result in a greater likelihood of offending. Criminal justice intervention has many "collateral consequences" including interruption of education, possible loss of employment, and attenuation of prosocial bonds (e.g., Laub \& Sampson, 1993). A large number of empirical studies over many decades have reported that official sanctions or severity of sanctions are associated with a greater likelihood of future offending. For example, in a twoyear follow-up of 414 adolescents (age 17 years), having prior incarcerations was one of the best predictors of entry into the adult correctional system (Benda et al., 2001). The effect is not limited to serious sanctions like incarceration, but has even included adverse effects of mere adjudication. Those most likely to offend in young adulthood are those who committed offenses in adolescence and we earlier discussed the many propositions about stability. In contrast with factors that are largely out of the control of policy makers such as family income and intel- 
lectual ability, criminal justice interventions are completely amenable to manipulation. They should be used as a tool to interrupt the continuity of offending, and yet the findings suggest that, on average, they exacerbate the problem. Further research is needed to develop a comprehensive understanding of system effects, by intervention type, in order to identify areas where policies can be changed to minimize future offending.

\section{Conclusion}

This review points to several factors consistently associated with persistent antisocial behavior in emergent adulthood (e.g., previous antisocial behavior, early onset, intelligence, academic achievement, abuse victimization, enduring marriage, peer deviance, drug abuse, and criminal justice intervention). But it is also clear that some important questions remain. We highlight the ones of greatest concern to us. First, despite a great deal of attention to the construct of low self-control, there is a strong possibility that the findings have been confounded. Future research must disentangle the effects of low self-control to ensure that associations between impulsivity and offending are not merely reflecting stability in conduct problems. The findings on high school dropout and school attainment are also much less consistent than we might expect. It could be the case that the beneficial effect of education on offending tops out at some point shortly after high school, but the association is not yet clear. Findings on the role of drug and alcohol abuse suggest that they slow desistance, though the mixed findings on the topic also suggest that the extent of use and the type of drug used may be important areas for further inquiry. Similarly, while the association between "enduring marriage" and young adult offending is fairly clear, other questions about marriage and offending remain related to the age at which marriage can have a beneficial effect, the impact of antisocial behavior of the spouse, and race and sex differences. Further, controls for maturation in within-subjects designs are needed as are more studies correcting for selection biases.

The unexpected findings on work and young adult offending should encourage further research on this topic. Numerous studies, not reviewed here, show that adolescents who work are more, not less, prone to offend, but theory predicting an association between having a good job and desistance remains highly compelling. Thus, examining age-by-age effects, across various circumstances, would be of keen interest, as would understanding the way criminal opportunities afforded by work may offset its benefits.

Poverty is one of the few factors that we believe could help explain adult-onset offending which we would predict might occur for youths with weak ties to parents, such as juvenile offenders and those exiting foster care. Social support might be something that could be leveraged by the system to mitigate the many stressors in those most vulnerable at this age.

We feel that a very important focus of future research on persistent offending into adulthood should be on high risk populations such as youthful offenders and foster children. So far, research suggests that, rather than serving as a deterrent, criminal justice interventions frequently have adverse effects on delinquents, so research shedding light on the effects of specific interventions, or on protective factors (such as social support) that mitigate the effects of involvement in the juvenile justice system, is very important.

\section{REFERENCES}

Arum, R., \& Beattie, I. (1999). High school experience and the risk of adult incarceration. Criminology, 37, 515-539. doi:10.1111/j.1745-9125.1999.tb00495.x

Ayers, C. D., Williams, J. H., Hawkins, J. D., Peterson, P. L., Catalano, R. F., \& Abbott, R. D. (1999). Assessing correlates of onset, escalation, deescalation, and desistance of delinquent behavior. Journal of Quantitative Criminology, 15, 277-306. doi:10.1023/A:1007576431270

Benda, B. B., Corwyn, R. F., \& Toombs, N. J. (2001). Recidivism among adolescent serious offenders: Prediction of entry into the correctional system for adults. Criminal Justice and Behavior, 28, 588613. doi:10.1177/009385480102800503

Blokland, A. (2005). Crime over the lifespan: Trajectories of criminal behavior in Dutch offenders. Leiden, Netherlands: Institute for the Study of Crime and Law Enforcement.

Bui, H. N., \& Morash, M. (2010). The impact of network relationships, prison experiences, and internal transformation on women's success after prison release. Journal of Offender Rehabilitation, 49, 1-22. doi:10.1080/10509670903435381

Cohen, P., Kasen, S., Smailes, E., \& Fagan, J. (2002). Childhood antecedents of adolescent and adult crime and violence, final report (Grant Number 1999-IJ-CX-0029). Washington DC: National Institute of Justice.

Cottle, C. C., Lee, R. J., \& Heilbrun, K. (2001). The prediction of criminal recidivism in juveniles: A meta-analysis. Criminal Justice and Behavior, 28, 367-394. doi:10.1177/0093854801028003005

Cullen, F. T., \& Wright, J. P. (1997). Liberating the anomie-strain paradigm: Implications from social support theory. In N. Passas, \& R. Agnew (Eds.), The future of anomie theory (pp. 187-206). Boston, MA: Northeastern University Press.

DeLisi, M., \& Vaughn, M. G. (2008). The Gottfredson-Hirschi critiques revisited: Reconciling self-control theory, criminal careers, and career criminals. International Journal of Offender Therapy and Comparative Criminology, 52, 520-537. doi:10.1177/0306624X07308553

Ellis, S., \& Savage, J. (2009). Strain, social support and persistent criminality. In J. Savage (Ed.), The development of persistent criminality (pp. 71-89). New York: Oxford University Press, Inc. doi:10.1093/acprof:oso/9780195310313.003.0004

Farrington, D. P. (2000). Psychosocial predictors of adult antisocial personality and adult convictions. Behavior Sciences \& the Law, 18, 605-622.

doi:10.1002/1099-0798(200010)18:5<605::AID-BSL406>3.0.CO;2$\underline{0}$

Farrington, D. P., \& West, D. J. (1995). Effects of marriage, separation and children on offending by adult males. In Z. S. Blau, \& J. Hagan (Eds.), Current perspectives on aging and the life cycle: Vol. 4. Delinquency and disrepute in the life course (pp. 249-281). Greenwich, CT: JAI Press.

Fergusson, D. M., Horwood, L. J., \& Nagin, D. S. (2000). Offending trajectories in a New Zealand birth cohort. Criminology, 38, 525-552. doi:10.1111/j.1745-9125.2000.tb00898.x

Gottfredson, M., \& Hirschi, T. (1990). A general theory of crime. Stanford, CA: Stanford University Press.

Hirschi, T. (1969). Causes of delinquency. Berkeley, CA: University of California Press.

Hoeve, M., Smeenk, W., Loeber, R., Stouthamer-Loeber, M., van der Laan, P. H., Gerris, J. R. M., \& Dubas, J. S. (2007). Long-term effects of parenting and family characteristics on delinquency of male young adults. European Journal of Criminology, 4, 161-194. doi:10.1177/1477370807074854

Horney, J., Osgood, D. W., \& Marshall, I. H. (1995). Criminal careers in the short-term: Intra-individual variability in crime and its relation to local life circumstances. American Sociological Review, 60, 655673. doi:10.2307/2096316

Hussong, A. M., Curran, P. J., Moffitt, T. E., Caspi, A., \& Carrig, M. M. (2004). Substance abuse hinders desistance in young adult's antisocial behavior. Development and Psychopathology, 16, 1029-1046. doi:10.1017/S095457940404012X 
Johnson, W., McGue, M., \& Iacono, W. G. (2009). School performance and genetic and environmental variance in antisocial behavior at the transition from adolescence to adulthood. Developmental Psychology, 45, 973-987. doi:10.1037/a0016225

King, R. D., Massoglia, M., \& MacMillan, R. (2007). The context of marriage and crime: Gender, the propensity to marry, and offending in early adulthood. Criminology, 45, 33-66 doi:10.1111/j.1745-9125.2007.00071.x

Lahey, B. B., \& Loeber, R. (1997). Attention-deficit/hyperactivity disorder, oppositional defiant disorder, conduct disorder, and adult antisocial behavior: A life span perspective. In D. M. Stoff, J. Breiling, \& J. D. Maser (Eds.), Handbook of antisocial behavior (pp. 51-59). New York: John Wiley.

Laub, J. H., Nagin, D. S., \& Sampson, R. J. (1998). Trajectories of change in criminal offending: Good marriages and the desistance process. American Sociological Review, 63, 225-238. doi:10.2307/2657324

Laub, J. H., \& Sampson, R. J. (1993). Turning points in the life course: Why change matters to the study of crime. Criminology, 31, 301326. doi:10.1111/j.1745-9125.1993.tb01132.x

Laub, J. H., \& Sampson, R. J. (2003). Shared beginnings, divergent lives: Delinquent boys to age 70. Cambridge, MA: Harvard University Press.

McGloin, J. M, \& Stickle, W. P. (2011). Influence or convenience? Disentangling peer influence and co-offending for chronic offenders. Journal of Research in Crime and Delinquency, 48, 419-447. doi:10.1177/0022427810393019

Moffitt, T. E. (1993). Adolescence-limited and life-course-persistent antisocial behavior: A developmental taxonomy. Psychological Review, 100, 674-701. doi:10.1037/0033-295X.100.4.674

Moffitt, T. E. (2003). Life-course-persistent and adolescence-limited antisocial behavior: A 10-year research review and a research agenda. In B. B. Lahey, T. E. Moffitt, \& A. Caspi (Eds.), Causes of conduct disorder and juvenile delinquency (pp. 49-75). New York: Guilford.

Moffitt, T. E. (2006a). A review of research on the taxonomy of lifecourse persistent versus adolescence-limited antisocial behavior. In F. T. Cullen, J. P. Wright, \& K. Belvins (Eds.) Taking stock: The status of criminological theory: Vol. 15 (pp. 277-311). New Brunswick, NJ: Transaction Publishers.

Moffitt, T. E. (2006b). Life-course persistent versus adolescence-limited antisocial behavior. In D. Cicchetti, \& D. Cohen (Eds.), Developmental psychopathology: Vol. 3. Risk, disorder and adaptation (pp. 570-598). New York: Wiley.

Morizot, J., \& Le Blanc, M. (2003). Continuity and change in personality traits from adolescence to midlife: A 25-year longitudinal study comparing representative and adjudicated men. Journal of Personality, 71, 705-755. doi:10.1111/1467-6494.7105002

Pagani, L. S. (2009). The influence of family context on the development and persistence of antisocial behavior. In J. Savage (Ed.), The development of persistent criminality (pp. 37-53). New York: Oxford University Press. doi:10.1093/acprof:oso/9780195310313.003.0002

Patterson, G. R., Reid, J. B., \& Dishion, T. J. (1992). A social learning approach: Vol. 4. Antisocial boys. Eugene, OR: Castalia.

Piquero, A. R., Farrington, D. P., \& Blumstein, A. (2007). Key issues in criminal career research: New analyses of the Cambridge study in delinquent development. Cambridge: Cambridge University Press.
doi:10.1017/CBO9780511499494

Pratt, T. C., \& Cullen, F. T. (2000). The empirical status of Gottfredson and Hirschi's general theory of crime: A meta-analysis. Criminology, 38, 931-964. doi:10.1111/j.1745-9125.2000.tb00911.x

Raine, A., Loeber, R., Stouthamer-Loeber, M., Moffitt, T. E., Caspi, A., \& Lynam, D. (2005). Neurocognitive impairments in boys on the life-course persistent antisocial path. Journal of Abnormal Psychology, 114, 38-49. doi:10.1037/0021-843X.114.1.38

Robins, L. (1966). Deviant children grown up. Baltimore, MD: Williams \& Wilkins.

Sampson, R. J., \& Laub, J. H. (1993). Crime in the making: Pathways and turning points through life. Cambridge, MA: Harvard University Press.

Sampson, R. J., Laub, J. H., \& Wimer, C. (2006). Does marriage reduce crime? A counterfactual approach to within individual causal effects. Criminology, 44, 465-508. doi:10.1111/j.1745-9125.2006.00055.x

Savage, J. (2009). Understanding persistent offending: Linking developmental psychology with research on the criminal career. In J. Savage (Ed.), The development of persistent criminality (pp. 3-36). New York: Oxford University Press. doi:10.1093/acprof:oso/9780195310313.001.0001

Schroeder, R. D., Giordano, P. C., \& Cernkovich, S. A. (2007). Drug use and desistance processes. Criminology, 45, 191-222. doi:10.1111/j.1745-9125.2007.00076.x

Stouthamer-Loeber, M., Wei, E., Loeber, R., \& Masten, A. S. (2004). Desistance from persistent serious delinquency in the transition to adulthood. Development and Psychopathology, 16, 897-918. doi:10.1017/S0954579404040064

Theobald, D., \& Farrington, D. P. (2009). Effects of getting married on offending. European Journal of Criminology, 6, 496-516. doi:10.1177/1477370809341226

Thornberry, T. P., Henry, K. L., Ireland, T. O., \& Smith, C. A. (2010). The causal impact of childhood-limited maltreatment and adolescent maltreatment on early adult adjustment. Journal of Adolescent Health, 46, 359-365. doi:10.1016/j.jadohealth.2009.09.011

Vila, B. (1994). A general paradigm for understanding criminal behavior: Extending evolutionary ecological theory. Criminology, 32, 311359. doi:10.1111/j.1745-9125.1994.tb01157.x

Warr, M. (1998). Life-course transitions and desistance from crime. Criminology, 36, 183-216. doi:10.1111/j.1745-9125.1998.tb01246.x

Werner, E. E., \& Smith, R. S. (1992). Overcoming the odds: High risk children from birth to adulthood. Ithaca, NY: Cornell University Press.

Widom, C. S. (1989). Child abuse, neglect, and violent criminal behavior. Criminology, 27, 251-271. doi:10.1111/j.1745-9125.1989.tb01032.x

Wiesner, M., \& Windle, M. (2004). Assessing covariates of adolescent delinquency trajectories: A latent growth mixture. Journal of Youth and Adolescence, 33, 431-442. doi:10.1023/B:JOYO.0000037635.06937.13

Wright, B. R. E., Caspi, A., Moffitt, T. E., \& Silva, P. A. (2001). The effects of social ties on crime vary by criminal propensity: A lifecourse model of interdependence. Criminology, 39, 321-351. doi:10.1111/j.1745-9125.2001.tb00925.x 